\title{
The Role of Sundanese Letters as the One of Identity and Language Preserver
}

\author{
Elis Suryani Nani Sumarlina ${ }^{1}$, Rangga Saptya Mohamad Permana ${ }^{2}$, \\ Undang Ahmad Darsa ${ }^{3}$ \\ ${ }^{1,3}$ Departemen Sejarah dan Filologi, Fakultas Ilmu Budaya, Universitas Padjadjaran \\ ${ }^{2}$ Program Studi Televisi dan Film, Fakultas Ilmu Komunikasi, Universitas Padjadjaran \\ ${ }^{1}$ elis.suryani@gmail.com, ${ }^{2}$ ranggasaptyamp@gmail.com, \\ ${ }^{3}$ undang.a.darsa@unpad.ac.id,
}

\begin{abstract}
Humans have the creativity, sense, and also the intention to be the differentiator from other creatures in this world. For this reason, humans have the ability to express their feelings and thoughts through a variety of languages, but not all ethnic groups accept characters and languages at the same time, depending on 'awareness' about the importance of signs to prove the form of creativity, sense, and the intention. Based on that awareness, there arises letters or writings, which are closely related to language. The language itself changes with the times, as well as other cultural elements. In the current era of globalization, local languages, especially Sundanese, are considered burdensome, because according to their successors it is more difficult to learn than other lessons. Perhaps this also causes young people to be reluctant to use their mother tongue. Young people are now more proud of foreign languages than their own mother tongue. Local scripts and languages seem marginalized, as if there is no longer the pride of young people now on the characters and mother tongue, also their identity. If this is allowed, in the future, the characters and local languages are like foreign languages which are difficult to understand. If so, what will happen to the characters and mother tongue in the future? To achieve more optimal educational and teaching objectives, strategies and methodologies are needed for teaching language that are reliable and capable. Language is closely related to letters, which functions to record the 'voices' of the language spoken orally and in writing. In addition, script, language, and literature are one of the tools of cultural preservation, which are contained in the form of texts as cultural relics of the past.
\end{abstract}

\section{Keywords: Sundanese letters; identity; language preserver}

\section{PENDAHULUAN}

Aksara merupakan lambang kemajuan adab dan media untuk memacu perkembangan peradaban. Oleh sebab itu, sudah selayaknya aksara memberi pencerahan dan kareueus 'kebanggaan' bagi setiap suku bangsa yang memiliki 'aksara' sebagai identitas dan jati dirinya. Masyarakat Sunda seperti halnya sebelas aksara lainnya di Indonesia, sejak bihari 'zaman dahulu' sudah mengenal dan menciptakan aksara sebagai hasil kreasi suku bangsanya sendiri, seperti halnya aksara Bali, aksara Batak, aksara Bengkulu, aksara Bima, aksara Bugis, aksara Jawa, aksara Komering, aksara Lampung, aksara Makassar [1], aksara Pasemah, dan aksara Rejang, yang digunakan untuk mengabadikan pengetahuan pengalamannya, dapat dianggap momentum penting serta menandakan tingginya tingkat peradaban yang pernah dicapai oleh masyarakat Sunda pada masa silam, suatu hal yang menjadi kareueus 'kebanggaan' kita sebagai ahli warisnya [2]. 
Kita sebagai penerus bangsa, perlu mengenal aksara sebagai warisan karuhun nenek moyang, yang telah menyumbangkan karya ciptanya bagi kemajuan dan perkembangan peradaban, untuk memahami makna keberadaan, peranannya, serta mengungkap kearifan lokal yang ada di dalamnya. Untuk itu, kita sebagai pewarisnya wajib memelihara, melestarikan, dan mengembangkan, serta memperkenalkannya kepada generasi muda berikutnya.

Informasi, tulisan, atau ulasan berkenaan dengan upaya ngaraksa, ngariksa, tur ngamumulé 'memelihara dan melestarikan' budaya Sunda, sungguh sangat menarik perhatian kami. Akhir-akhir ini di beberapa sekolah di Jawa Barat misalnya, ramai dibicarakan pemberlakuan mata pelajaran muatan lokal dan penggunaan bahasa asing, khususnya bahasa Inggris. Pro dan kontra pun bermunculan. Namun tulisan ini tidak untuk memolemikkan masalah tersebut, kami lebih fokus terhadap aksara Sunda, yang jelas-jelas menjadi jati diri tur ajén diri 'identitas dan kebanggaan' masyarakat Sunda, yang justru keberadaannya kini semakin katélér-télér 'terabaikan'. Mengapa pemerintah tidak memberlakukan implementasi aksara Sunda di sekolah-sekolah yang sudah jelas-jelas ada Kepres, SK dan Perdanya?

Darsa [3] [4] peneliti dan pengkaji naskah Sunda Kuno menyosialisasikan kembali aksara Sunda bersama Edi S. Ekadjati [5], dan Atja \& Saleh Danasasmita serta Ayatrohaedi dan Permadi, dkk. [6], menyebutkan bahwa sosialisasi aksara Sunda sudah diatur dalam Peraturan Daerah Provinsi Jawa Barat Nomor 5 tahun 2003, yang tentang Pemeliharaan Bahasa, Sastra, dan Aksara Daerah. Perda tersebut ditindaklanjuti dengan Perda nomor 4 tahun 2014, yang kemudian diikuti oleh SK pemberlakuan pengajaran bahasa Sunda di semua jenjang pendidikan, termasuk di dalamnya pengajaran aksara Sunda, yang tidak bisa dipisahkan dengan bahasa, karena aksara Sunda merupakan salah satu pelestari bahasa khususnya, dan budaya pada umumnya. Dengan adanya Peraturan Daerah dimaksud, generasi muda selayaknya ikut serta mendukung, dengan cara mengenal, mempelajari, mengimplementasikan, dan mengembangkannya.

Upaya sosialisasi dan implementasi aksara Sunda terus menerus dilaksanakan oleh pemerintah maupun kalangan perguruan tinggi dan masyarakat, melalui seminar, lokakarya, pelatihan, perlombaan membaca dan menulis aksara Sunda, lomba kaligrafi, pembuatan jam beraksara Sunda, maupun penerbitan buku. Standardisasi sekaligus font aksara Sunda pun pernah dilakukan oleh Disbudpar dan Dinas pendidikan, Museum Sri Baduga, Museum Geusan Ulun, Jarahnitra, dan kelompok sosial masyarakat Sunda, dengan melibatkan para ahli dari Unpad, UI, dan UPI.

Sosialisasi dan implementasi aksara Sunda kepada guru atau generasi muda Sunda membutuhkan strategi dan metodologi pengajaran yang andal dan mumpuni. Untuk itu, Para pegiat dan pelaksana pendidikan sepatutnya mencari solusi dan menyiasati bagaimana 'strategi dan metodologi pengajaran' aksara, bahasa, sastra, dan budaya darah yang dapat diterapkan di semua jenjang pendidikan, sesuai dengan kurikulum yang berlaku, agar muatan lokal yang diajarkan mudah diterima dan dicerna oleh anak didik. Hal ini penting, karena pelajaran bahasa daerah, khususnya bahasa Sunda di sekolah belum cukup memadai. Berkaitan dengan masalah ini, peran orang tua dibutuhkan untuk mengenalkan dan mengajarkan aksara dan bahasa Sunda kepada anak-anaknya di lingkungan keluarga. Aksara Sunda yang merupakan identitas orang Sunda, keberadaannya kini belum begitu diperhatikan, karena banyak orang Sunda yang belum kenal dan belum mampu membacanya. Untuk itu, sewajarnyalah kalau pemerintah dan instansi terkait bersama-sama menyosialisasikan dan mengimplementasikan aksara Sunda dimaksud, sejalan dengan Kepres, SK dan Perda yang sudah ada, yang berperan pula sebagai pelestari bahasa dan budaya. 


\section{METODE PENELITIAN}

Metode penelitian yang digunakan untuk meneliti masalah aksara Sunda adalah metode penelitian deskriptif analisis, yang berusaha mendeskripsikan data dan fakta aksara yang ada dalam naskah Sunda Kuno abad XVI Masehi. Metode kajian menggunakan metode kajian filologi, melalui tahapan kodikologis dan tekstologis, melalui tahapan heuristik, seleksi data, gradasi/seleksi tahap utama, dan presentasi data aksara, baik fonem vokal, fonem konsonan, vokalisasi, tanda baca, dan ejaan yang digunakan saat naskah itu ditulis [7]. Sumber data penelitian adalah naskah 'dokumen budaya yang ditulis tangan', berbahan lontar dan nipah [8], beraksara dan berbahasa Sunda Kuno, yang ditulis abad XVI Masehi. Transliterasi teks dan kajian naskah yang sudah digarap oleh filolog, khususnya teks naskah yang beraksara dan berbahasa Sunda Kuno, yang mengenalkan dan menjelaskan cara menulis dan membaca aksara Sunda, di samping sistem dan tatacara penulisan aksara Sunda [9], serta buku-buku filologi, yang berkaitan dengan sejarah perkembangan aksara dan bahasa Sunda .

\section{HASIL DAN PEMBAHASAN}

\subsection{Sejarah Perkembangan Aksara dan Bahasa Sunda}

Mengapa kita sebagai pewaris budaya berkewajiban memelihara, melestarikan, dan mengembangkan sejarah dan budaya nenek moyang? Hal ini ditengarai karena kehidupan saat ini berakar dari sejarah dan budaya masa silam, yang berguna, untuk mengungkap tonggak sejarah perkembangan aksara dan bahasa Sunda yang ada saat ini.

Bukti-bukti tertulis yang sudah ditemukan di wilayah Tatar Sunda dapat dijadikan 'ciri' untuk menelurusi aksara yang pernah berkembang serta digunakan di Tatar Sunda. Terdapat tujuh jenis aksara yang pernah dikenal dan digunakan dalam tradisi tulis di masyarakat Sunda, berturut-turut sesuai dengan waktu pemakaiannya, yakni aksara Pallawa, aksara Pranagari (digunakan abad ke-5 hingga abad ke-7 Masehi; \pm selama 3 abad),, aksara Sunda Kuno (abad ke-14 hingga abad ke18 Masehi; \pm selama 5 abad), Aksara Jawa (yang disebut aksara Carakan) yang digunakan pada abad ke-11 dan abad ke-17 hingga abad ke-19 Masehi; \pm selama 4 abad), aksara Arab (disebut juga dengan istiah aksara Pegon, digunakan pada abad ke-17 hingga pertengahan abad ke-20 Masehi; \pm selama 3 abad),), aksara Cacarakan, yang dipakai pada abad ke-11 dan abad ke-17 hingga abad ke-19 Masehi; \pm selama 4 abad), dan aksara Latin digunakan pada (akhir abad ke-19 hingga sekarang) [10] [11] [12] [13] [14] [15].

Aksara yang dikenal dan digunakan, khususnya aksara yang digunakan untuk menulis teks naskah Sunda, serta disesuaikan dengan bahasa yang berkembang di Tatar Sunda, hanya digunakan empat jenis aksara, yakni: Aksara Sunda Kuno, aksara Sunda-Jawa (Cacarakan/Hanacaraka), aksara Arab (Pegon), dan aksara Latin [13]. Menurut Moriyama [12] masyarakat di Jawa Barat, jauh sebelum orang Eropa sampai ke wilayah ini sebenarnya telah mengenal satu bahasa yang lain, yang menggunakan aksara yang berbeda dari aksara Jawa dan Aksara Arab. Sejumlah inskripsi dan teks [13] seperti Bujangga Manik dan Carita Parahiyangan [10] [11] [16] merupakan bukti sejarah tentang apa yang sekarang disebut bahasa Sunda Kuno. Bahasa itu, lengkap dengan aksaranya yang khas, sudah digunakan di daerah Sunda sebelum pengaruh Mataram-Jawa menyebar di wilayah ini pada abad ke-17, namun tersisihkan begitu bahasa Jawa mulai mendesakkan pengaruhnya di wilayah penutur bahasa Sunda pada abad ke-18.

Moriyama [12] [13] mengungkapkan bahwa: "Sebelum aksara Latin diperkenalkan oleh Belanda di wilayah penutur bahasa Sunda pada abad ke-19, bahasa Sunda sudah ditulis dalam 
aksara Arab (Pegon), selain dalam aksara Jawa. Aksara Arab diperkenalkan oleh para sarjana Muslim sejak abad ke-15 dan digunakan di lingkungan sekitar institusi-institusi agama Islam. Aksara Jawa diperkenalkan sejak abad ke-17, ketika pengaruh kerajaan Mataram mulai terasa di bagian barat pulau Jawa, dan kaum ménak (bangsawan lokal) mengikuti teladan dalam bahasa Jawa yang menunjukkan perasaan kagum mereka terhadap istana-istana di Jawa Tengah (Yogyakarta dan Surakarta). Aksara Arab digunakan dalam hampir semua jenis tulisan, sedangkan aksara Jawa hanya digunakan untuk menulis laporan-laporan resmi kepada dinasti Mataram-Jawa, dan belakangan kepada pemerintah Belanda, selain dalam korespondensi di kalangan ménak. Para administrator Belanda yang menjalankan kembali roda keuasaan Belanda di Jawa Barat setelah pemerintahan peralihan Inggris berakhir, bekerjasama dengan para menak dan hampir tidak menyadari bahwa para intelektual lokal juga menggunakan aksara Arab. Tidak heran, ketika mendirikan sekolah, para administrator itu hanya memperhitungkan aksara Jawa, selain aksara Latin".

Sementara itu, perkembangan bahasa Sunda berkelindan erat dengan perkembangan aksara itu sendiri, karena aksara berfungsi untuk merekam bunyi bahasa, agar semua informasi bisa tersebar dan digunakan sebagai alat komunikasi dalam masyarakat, baik secara lisan maupun tulisan,. Dengan demikian, tidak bisa kita pungkiri bahwa bahasa Sunda merupakan hasil kreativitas masyarakat Sunda [17], yang tumbuh dan berkembang sesuai dengan perkembangan zaman.

Terdapat empat bahasa berkenaan dengan penggunaan bahasa yang digunakan dalam penulisan naskah-naskah Sunda di Jawa Barat, sebagaimana dikemukakan [5] [18] [14] Bahasa Sunda Bihari (Bahasa Sunda Kuno) yang digunakan pada naskah-naskah Sunda Kuno abad XVI Masehi, yang beraksara Sunda (Kuno), berbahan lontar atau nipah, ada perbedaan khususnya dalam kosakata, struktur, serta makna katanya dengan naskah-naskah Sunda yang ditulis abad XVII M. sampai abad XVII-XIX Masehi, yang menggunakan aksara Cacarakan (Aksara Carakan dalam Aksara Jawa), maupun aksara Pegon (aksara Arab berbahasa Sunda) XVII-XIX serta dengan naskah Sunda yang ditulis abad XIX Masehi sampai sekarang, menggunakan aksara Latin [5] [11] [19].

Sejarah perkembangan bahasa Sunda andai mengacu serta dikaitkan dengan keberadaan, peran, serta sejarah perkembangan sastra Sunda di masyarakat, terbagi menjadi tiga periode, yakni: Jaman Buhun, Jaman Kemarin, dan Jaman Kini, sebagaimana dikemukakan Ajip Rosidi ketika menanggapi periodisasi yang dikemukakan R.I. Adiwidjaja dan M.A. Salmun (dalam [19]. Mengacu kepada periodisasi tersebut, berdasar bahan dan data yang terungkap lewat prasasti, naskah, maupun karya sastra lainnya yang berkembang di masyarakat Tatar Sunda, maka secara umum, sejarah perkembangan bahasa Sunda sejak dahulu hingga sekarang, dapat dibagi menjadi tiga zaman: yakni Bahasa Sunda Zaman Bihari/Buhun, Bahasa Sunda Zaman Klasik/Peralihan, dan Bahasa Sunda Zaman Kiwari 'masa kini'[20].

Menurut Moriyama [12] [13] masyarakat di Jawa Barat, jauh sebelum orang Eropa sampai ke wilayah ini sebenarnya telah mengenal satu bahasa yang lain, yang menggunakan aksara yang berbeda dari aksara Jawa dan Aksara Arab. Sejumlah inskripsi dan teks [13] seperti Bujangga Manik dan Carita Parahiyangan [19] [3] merupakan bukti-bukti sejarah tentang apa yang sekarang disebut bahasa Sunda Kuno. Bahasa itu, lengkap dengan aksaranya yang khas, sudah digunakan di daerah Sunda sebelum pengaruh Mataram-Jawa menyebar di wilayah ini pada abad ke-17, namun tersisihkan begitu bahasa Jawa mulai mendesakkan pengaruhnya di wilayah penutur bahasa Sunda pada abad ke-18.

Naskah Sunda Abad XVI Masehi, beraksara Sunda (Kuno), berbahasa Sunda (Kuno), seperti Naskah Sanghyang Siksakandang Karesian, Naskah Carita Parahiyangan, Carita Pragmen Carita Parahiyangan, Amanat Galunggung atau Darma Siksa, Sanghyang Raga 
Dewata, Kawih Paningkes dan Sewaka Darma, berjenis puisi dan prosa, bahasanya belum dipengaruhi oleh bahasa Jawa yang memiliki unggah-ungguh basa (undak-usuk basa (dalam bahasa Sunda)), bahasa Arab, bahasa Melayu, serta bahasa Belanda. Naskah Sunda abad XVII dan XVIII yang beraksara Cacarakan, berbahasa Sunda peralihan sudah menggunakan undak-usuk basa (tingkatan bahasa), jenis puisi menggunakan pupuh guguritan dan wawacan, yakni puisi yang digubah dalam bentuk dangding atau lagu, yang memiliki aturan gurulagu, guruwilangan, dan gurugatra dalam setiap pada 'bait' dan padalisan 'baris'. Selain itu, naskah Sunda beraksara Arab dan berbahasa Sunda (Pegon) dipengaruhi oleh bahasa Arab, bahasa Melayu dan Belanda. Ditulis menggunakan jenis syair atau puisi pupujian. Sementara itu, naskah Sunda beraksara Latin, abad XIX sampai sekarang, selain berbahasa Sunda kiwari (masa kini), juga dipengaruhi oleh bahasa Jawa, bahasa Arab, dan bahasa Melayu, berjenis prosa, puisi (wawacan atau pupujian), dan syair, berbahan kertas Eropa [10] [11].

Aksara senantiasa berkelindan erat dengan bahasa dan budaya. Kita juga perlu mengenal aksara sebagai warisan karuhun nenek moyang, dalam upaya menggali, meneliti, memelihara, melestarikan, dan mengembangkan, serta memperkenalkannya kepada generasi muda, untuk memahami makna keberadaan, peranannya, serta mengungkap kearifan lokal yang ada di dalamnya, di samping sebagai identitas dan jati diri suatu bangsa naupun suku bangsa.

\subsection{Strategi dan Metodologi Pembelajaran Aksara Sunda}

Metodologi pengajaran yang harus dikuasai seorang Guru merupakan cara atau jalan. Sementara itu pendekatan, adalah tanggapan atau pandangan mengenai ciri-ciri, mempelajari, dan mengajarkan bahan ajar. Metode yaitu beragam skenario atau rancangan untuk menyampaikan bahan ajar dalam rangka merealisasikan pendekatan dimaksud. Teknik berdasar atas kejadian aktual atau proses operasional di dalam kelas [21] [22].

Strategi merupakan rancangan yang cermat mengenai kegiatan untuk mencapai tujuantujuan khusus (KBBI, dalam [21] [22], yang mengacu kepada dua hal, yakni: rencana atau taktik dan prosedur. Dalam pengajaran, strategi merupakan salah satu ragangan yang dilakukan dengan sadar serta berkesinambungan, yang hendak dilakukan untuk mencapai tujuan pengajaran. Selain srategi, metodologi, dan rencana pembelajaran, yang tidak kalah pentingnya adalah mempersiapkan sarana dan prasarana yang menunjang terhadap keberhasilan pewarisan ilmu dan pengetahuan kepada anak didiknya.

Pengajaran budaya Sunda secara integral, khususnya aksara Sunda menuntut Guru untuk mengajarkan dan membimbing siswa agar termotivasi', ikut serta berperan aktif, serta kreatif'. Bukan hanya pengetahuannya, namun juga kemahiran serta sikap. Siswa diharapkan mampu mengenal, mengerti, dan mengimplementasikan aksara Sunda dengan mahir dan terampil (baca tulis), menurut kaidah yang ditentukan. Kita paham bahwa tidak ada strategi dan metodologi yang paling handal dan mumpuni, karena strategi dan metodologi dimaksud tergantung kepada guru, siswa, bahan ajar, tempat, waktu, dan sarana serta prasarana pengajaran [21].

Apapun strategi dan metodologi yang digunakan oleh seorang guru, yang terpenting guru harus ikut 'berkiprah' agar siswa membiasakan diri mengimplementasikan aksara Sunda di lingkungan sekolah. Dengan bimbingan dan arahan para Guru, secara lambat laun, masalah yang berkaitan dengan aksara dan bahasa Sunda, akan mudah diatasi. Saat ini yang terpenting adalah bahwa siswa ada kemauan dan kebanggaan terhadap aksara dan bahasa daerahnya. Pemerintah Daerah Provinsi JawaBarat, melalui Dinas Pendidikan dan Kebudayaan harus berkiprah lebih optimal, agar bahasa termasuk aksara Sunda sebagai identitas dan jati diri 
orang Sunda dikenal dan dipelajari, serta diimplementasikan di masyarakat. Melalui pengenalan aksara Sunda, akan terimbas terhadap bahasa Sunda, yang harus tetap diwanohkan 'dikenalkan' dan digunakan oleh setiap keluarga di rumah, terutama 'ibu'. Karena ibu merupakan ujung tombak pendidikan secara informal. Dengan cara pengenalan dan pemakaian basa Sunda dalam lingkungan keluarga, bahasa 'Ibu' tidak akan ditakuti lagi oleh generasi mudanya, yang akhirnya bahasa Ibu akan digandrungi, digunakan, dan diimplementasikan dalam komunikasi sehari-hari.

Beberapa strategi pembelajaran aksara Sunda sesuai dengan metode yang digunakan, adalah: a. klasifikasi aksara antara fonem vokal dan fonem konsonan, b. seleksi aksara antara fonem vokal dan fonem konsonan, gradasi aksara antara fonem vokal dan fonem konsonan, mana aksara yang mirip dan mana yang tidak mirip. Vokalisasi diklasifikasi berdasarkan kedudukannya, antara vokalisasi yang disimpan di atas konsonan dan vokal, di sebelah konsonan dan vokal, serta di bawah konsonan dan vokal. sebagaimana tampak pada bagan berikut ini.

\section{SIMPULAN}

Ketidakpedulian terhadap aksara Sunda disebabkan ketidaksiapan Guru sebagai 'ujung tombak' untuk mengenalkan dan mengajarkan aksara Sunda kepada anak didiknya. Hal ini dimaklumi, karena.bagaimana Guru mau mengajarkan materi aksara Sunda, kalau dia sendiri belum memahami aksara Sunda dimaksud. Strategi dan metodologi pengajaran yang dilakukan dalam penelitian kami, yakni dengan cara mengklasifikasikan aksara antara fonem vokal dan fonem konsonan, lalu menyeleksi aksara antara fonem vokal dan fonem konsonan, menggradasi aksara antara fonem vokal dan fonem konsonan, serta dicari mana aksara yang mirip dan mana yang tidak mirip, menempatkan vokalisasi dengan cara yang tepat dan benar, serta mampu mengimplementasi dan mempraktekkan langsung aksara Sunda kepada anak didik melalui alat peraga yang sesuai dengan keterampilan pengajar dan siswa, akan lebih mudah dimengerti, dipahami dan dicerna oleh siswa ketimbang hanya mengajarkan teori semata.

Untuk mencapai tujuan pembelajaran aksara Sunda sesuai dengan yang diharapkan, dalam hal ini pemerintah daerah berkewajiban ikut berkiprah menyosialisasikan dan mengimplementasikan srategi dan metodologi pembelajaran aksara Sunda bagi Guru, pelaku budaya, generasi muda dan siswa dengan menerapkan teknik 'belajar sambil bermain'. Guru mampu mengajak anak didiknya untuk berperan aktif, dan mengimplementasikan strategi dan metodologi aksara Sunda dimaksud selama proses belajar mengajar. Salah satu implementasi aksara Sunda, setiap sekolah, instansi pemerintah, juga tempat wisata yang ada di daerahnya masing-masing dihimbau dan disarankan untuk membuat papan nama beraksara Sunda. Melalui usaha dimaksud, diharapkan para siswa secara tidak langsung mengenal dan belajar aksara Sunda serta menjadi pembelajaran kepada masyarakat sebagai wahana ilmu pengetahuan untuk memperkokoh pengajaran bahasa Sunda, agar merasa memiliki dan menyintai aksara dan bahasa Sunda sebagai identitas, jati diri dan kebanggaannya.

\section{REFERENCES}

[1] C. Pelras, "Orality and writing among the Bugis," Int. J. Asia-Pacific Stud., vol. 12, no. Supp. 1, pp. 13-51, 2016.

[2] D. Koswara, D. Haerudin, and R. Permana, "Nilai-nilai pendidikan karakter bangsa dalam khazanah sastra Sunda klasik: Transformasi dari kelisanan (orality) ke keberaksaraan (literacy) carita pantun Mundinglaya Di Kusumah (kajian struktural- 
semiotik dan etnopedagogi)," J. Penelit. Pendidik., vol. 14, no. 2, pp. 126-134, 2016.

[3] U. A. Darsa, "Identifikasi Bahasa Yang Hidup Pada Masa Pakuan Pajajaran,” 1991.

[4] U. A. Darsa, Aksara Sunda Kaganga Jeung Sistem Tata Tulisna: Materi Pangajaran Aksara Sunda. Bandung: Deatama, 2005.

[5] E. S. Ekadjati, "Naskah Sunda: Inventarisasi dan Pencatatan,” Bandung, 1988.

[6] T. Permadi, E. S. Ekadjati, U. A. Darsa, and I. Baidillah, Aksara Sunda. Bandung: PT. Granesia, 1999.

[7] E. S. N. Sumarlina, "Batari Hiyang Janapati dalam Perspektif Gender," JENTERA J. Kaji. Sastra, vol. 6, no. 2, pp. 181-196, 2017.

[8] A. Gunawan, "Nipah or gebang? A philological and codicological study based on sources from West Java," Bijdr. tot Taal-, Land- en Volkenkd., vol. 171, no. 2-3, pp. 249-280, 2015.

[9] Heriyanto and E. S. N. Sumarlina, "Place Branding Though the Linkage Between Metaphore, Sundanese Culture and the Characterisstics of the Tourist Destinations: West Java, Indonesia,” J. Kaji. Budaya dan Hum., vol. 1, no. 1, pp. 96-103, 2019.

[10] U. A. Darsa, Aksara Sunda. Bandung: Dinas Kebudayaan dan Pariwisata Provinsi Jawa Barat, 2007.

[11] E. S. Ekadjati, Direktori Edisi Naskah Nusantara. Jakarta: Masyarakat Pernaskahan Nusantara-Yayasan Obor Indonesia, 2000.

[12] M. Moriyama, Sundanese Print Culture and Modernity in 19th-Century West Java. Singapore: NUS Publishing, 2005.

[13] M. Moriyama, "Semangat Baru: Kolonialisme, Budaya Cetak, dan Kesusastraan Sunda Abad ke-19." Bandung, 2005.

[14] E. S. N. Sumarlina, Seni Budaya dan Kearifan Lokal. Bandung: PT. Raness Media Rancage, 2018.

[15] S. Danasasmita and Atja, "Sewaka Darma, Sanghyang Siksakandang Karesian, Amanat Galunggung: Transkripsi dan Terjemahan.” Bandung, 1987.

[16] J. Noorduyn and A. Teeuw, Three Old Sundanese Poems. Leiden: KITLV Press, 1993.

[17] Heriyanto, L. Manggong, and E. S. N. Sumarlina, "Baduy Cultural Tourism: An Ethnolinguistic Perspective,” Int. J. English Lit. Soc. Sci., vol. 4, no. 2, pp. 198-205, 2019.

[18] E. S. Ekadjati, Nu Maranggung Dina Sajarah Sunda. Bandung: Pusat Studi Sunda, 2016.

[19] E. S. N. Sumarlina, Budaya Sunda dalam Untaian Masa. Bandung: PT. Raness Media Rancage, 2018.

[20] Heriyanto, L. Manggong, and E. S. N. Sumarlina, "Language, Identity, and Cultural Tourism: An Ethnolinguistic Case-Study of Kampung Naga Tasikmalaya, Indonesia," Am. J. Humanit. Soc. Sci. Res., vol. 3, no. 3, pp. 50-56, 2019.

[21] Y. Sudaryat, "Padika Pangajaran Basa, Sastra, jeung Budaya Sunda di Sakola," 2011.

[22] H. G. Tarigan, Strategi Pengajaran dan Pembelajaran Bahasa. Bandung: Angkasa, 2009. 